closely watching patients receiving oxprenolol so that any adverse reactions may be detected at an early stage.

${ }^{1}$ Assem, E. S. K., Banks, R. A., Proceedings of the Royal Society of Medicine, $1973,66,179$. 2 Felix, R. H., Ive, F. A., and Dahl, M. C. G., British Medical fournal,

${ }^{3}$ Wright, P., British Medical fournal, 1975, 1, 595.

Department of Dermatology, University Hospital of Wales, Cardiff, CF4 4XN

P. J. A. HOLT, M.B., M.R.C.P., Senior Registrar

E. WADDINGTON, M.D., F.R.C.P., Consultant Dermatologist

\section{Glycerol Therapy for Cerebral Oedema Complicating Fulminant Hepatic Failure}

A recent analysis of the main causes of death in a consecutive series of 132 patients (96 deaths) with fulminant hepatic failure (F.H.F.) seen over a seven-year period showed cerebral oedema in $35(31 \%)$ of the 92 cases in which the brain was examined at necropsy. In 20 of these there was associated brain herniation, and in some cases death appeared to be due to cerebral oedema at a time when liver function was improving. The mechanism of the development of the oedema and its relation to the encephalopathy is unknown but clearly an effective means of control might improve the survival rate in this condition. Because of experience in neurosurgery, both dexamethasone and mannitol have been advocated in F.H.F. but the former may lead to gastrointestinal bleeding and the latter is often followed by a rebound increase in intracranial pressure. Glycerol given intravenously as a $10 \%$ solution in a dose of $50 \mathrm{~g}$ over 24 hours reduces the neurological deficit resulting from a cerebrovascular accident, possibly by limiting cerebral oedema, ${ }^{1}$ and there is one report of its successful use in F.H.F. ${ }^{2}$ As the liver is an important disposal site of endogenous glycerol liberated during lipolysis we have measured its concentration in blood in patients with F.H.F. and have also investigated the effect of infusion of a $10 \%$ solution.

\section{Case Histories} Eighteen untreated patients with F.H.F. who were in grade 4 hepatic coma
showed significantly higher $(P<0.05)$ basal whole blood glycerol concenshowed significantly higher $(\mathrm{P}<0.05)$ basal whole blood glycerol concentrations (mean $0.354 \pm \mathrm{SEM} 0.118 \mathrm{mmol} / \mathrm{l})$ than fasting control subjects
$(0.074 \pm 0.005 \mathrm{mmol} / \mathrm{l})$. Five further patients with F.H.F. who had deterio$(0.074 \pm 0.005 \mathrm{mmol} / \mathrm{l})$. Five further patients with F.H.F. who had deteriorated to grade 4 hepatic encephalopathy were treated with intravenous
glycerol in a dose of $50 \mathrm{~g} / 24$ hours but we could find no improvement in the level of consciousness. Further studies in two volunteer subjects showed that this dosage led to only a minor rise in blood glycerol concentration and no change in plasma osmolality. To produce an appreciable rise in blood glycerol concentration a further fasted control patient was given a loading dose of $6.5 \mathrm{~g}$ followed by $13 \mathrm{~g}$ over 40 minutes. With this dosage blood glycerol concentration rose to a maximum of $2.64 \mathrm{mmol} / 1$ at 40 minutes but this was not associated with an appreciable increase in plasma osmolality. Definite intravascular haemolysis occurred, however: plasma free haemoglobin rose to $70 \mathrm{mg} / 100 \mathrm{ml}$ at 40 minutes and plasma haptoglobin concentration fell sharply to less than $10 \mathrm{mg} / 100 \mathrm{ml}$ at 24 hours.

\section{Discussion}

Both endogenous and exogenous glycerol are removed principally in the liver and kidney and possibly this process is impaired in hepatic disease, which explains the significantly increased blood glycerol levels found in patients with F.H.F. The low dosage of intravenous glycerol (50 g/24 hours) given to these patients did not improve their level of consciousness and the benefit seen in patients with stroke given the same dose may be due to a direct effect on infarcted brain. Higher doses of intravenous glycerol may benefit cerebral oedema by an osmotic action and in patients with stroke given $17 \mathrm{~g} / \mathrm{h}$ there was an associated increase in cerebral hemisphere blood flow and a decrease in the respiratory quotient. Cerebrospinal fluid pressure decreased and no rebound occurred. ${ }^{3}$ Our results show, however, that similar doses may result in intravascular haemolysis and this has also been reported using other dosage schedules $(60-80 \mathrm{~g}$ of glycerol as a $20 \%$ solution over $15-60$ minutes and also after $50 \mathrm{~g}$ as a $10 \%$ solution over $60-90$ minutes). ${ }^{45}$

We conclude that intravenous infusion of $10 \%$ glycerol $(50 \mathrm{~g} /$ day $)$ is ineffective in improving encephalopathy in patients with F.H.F. and that higher doses may result in dangerous intravascular haemolysis.

The continued support of the Medical Research Council is gratefully acknowledged.

1 Mathew, N. T., et al., Lancet, 1972, 2, 1327.

2 Beallo, R., and Bernstein, R., Gastroenterology, 1973, 65, 527

3 Meyer, J.'S., et al., Stroke, $1972,3,168$.

5 Welch, K. M. A., et al., Lancet, 1974, 1, 416

Liver Unit, King's College Hospital and Medical School, SE5 8RX C. O. RECORD, M.B., M.R.C.P., Honorary Lecturer in Medicine (Present appointment: Senior Registrar, The London Hospital, London E1 1BB) R. A. CHASE, B.SC., Research Fellow

R. D. HUGHES, B.SC., PH.D., Research Fellow

IAIN M. MURRAY-LYON, M.D., M.R.C.P., Senior Lecturer in Medicine ROGER WILLIAMS, M.D., F.R.C.P., Director of the Liver Unit

\section{Modified Oesophagoscope for Injecting Oesophageal Varices}

Emergency operations for the arrest of bleeding from oesophageal varices carry a high mortality rate. ${ }^{1-4}$ Better results have been reported using injection of sclerosants through the oesophagoscope, ${ }^{5}$ but manipulating accurately the point of the needle at the distal end of the oesophagoscope is difficult. The technique is greatly simplified by modifying the $50-\mathrm{cm}$ Negus oesophagoscope after the style of the Gabriel proctoscope.

\section{Modification and Technique}

The modification consists of cutting a slot $0.5 \mathrm{~cm} \times 4.0 \mathrm{~cm}$ in the lower end of the instrument diagonally opposite the beak (see fig. (a)).

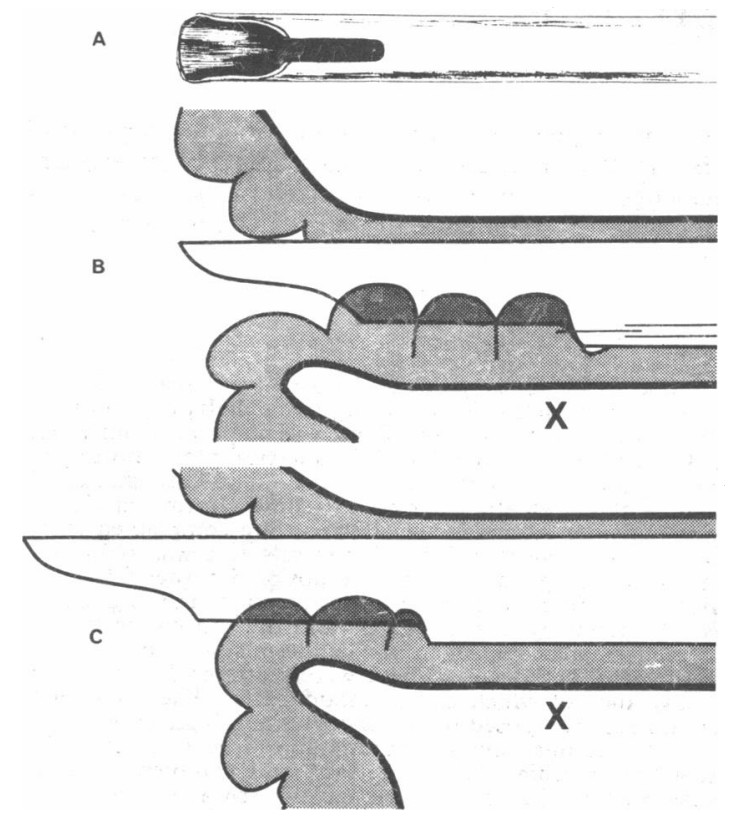

Modified oesophagoscope. (a) Slot cut in distal end. (b) Prolapse of varix and overlying mucosa into slot, which allows needle to be advanced directly into mass of varix. (c) Oesophagoscope advanced to compress site where injection has been given. 